\title{
THE REAL SECTOR: FACTORS AND TRENDS O. Izriadnova
}

Over the period of January-October 2016, the scale of business activity in the Russian economy was determined by the downward trends displayed by external and domestic demand that had emerged in the course of the previous years. The domestic market was negatively affected by the shrinking volumes of construction and investment in construction, as well as retail trade turnover, by $5.0 \%$ and $5.3 \%$ respectively, relative to the period of January-October 2015. As before, the main growth factors were agricultural production, mineral resources extraction, and pipeline transport indices.

The plunge, on previous year, of physical volumes of output in the basic types of economic activity has been registered since 2015. Economic instability is further enhanced by the declining investment activity, retail turnover, and industrial production indices. The construction work volume index for January-October 2016 amounted to $95.0 \%$, and that of retail trade turnover - to 94.7\%, compared with the same period of the previous year. In Q2 2016, after a plunge for five quarters in a row, the industrial production index demonstrated a slight growth, but this trend was not sustainable. Overall, the period-end industrial production index for January-October 2016 amounted to $100.3 \%$ as compared with its previous year's value, including $99.1 \%$ in the manufacturing industry. This year, similarly to the situation a year earlier, the positive components of the economic growth rate index were the growth rates in the sector of mineral resources extraction (102.2\% on JanuaryOctober 2015), agriculture (102.9\%), and transport (101.6\%).

This year saw the strengthening negative effects of the downward trend in domestic demand that has been evident for seven quarters in a row. The decline of overall demand indices in GDP has had to do with factors like

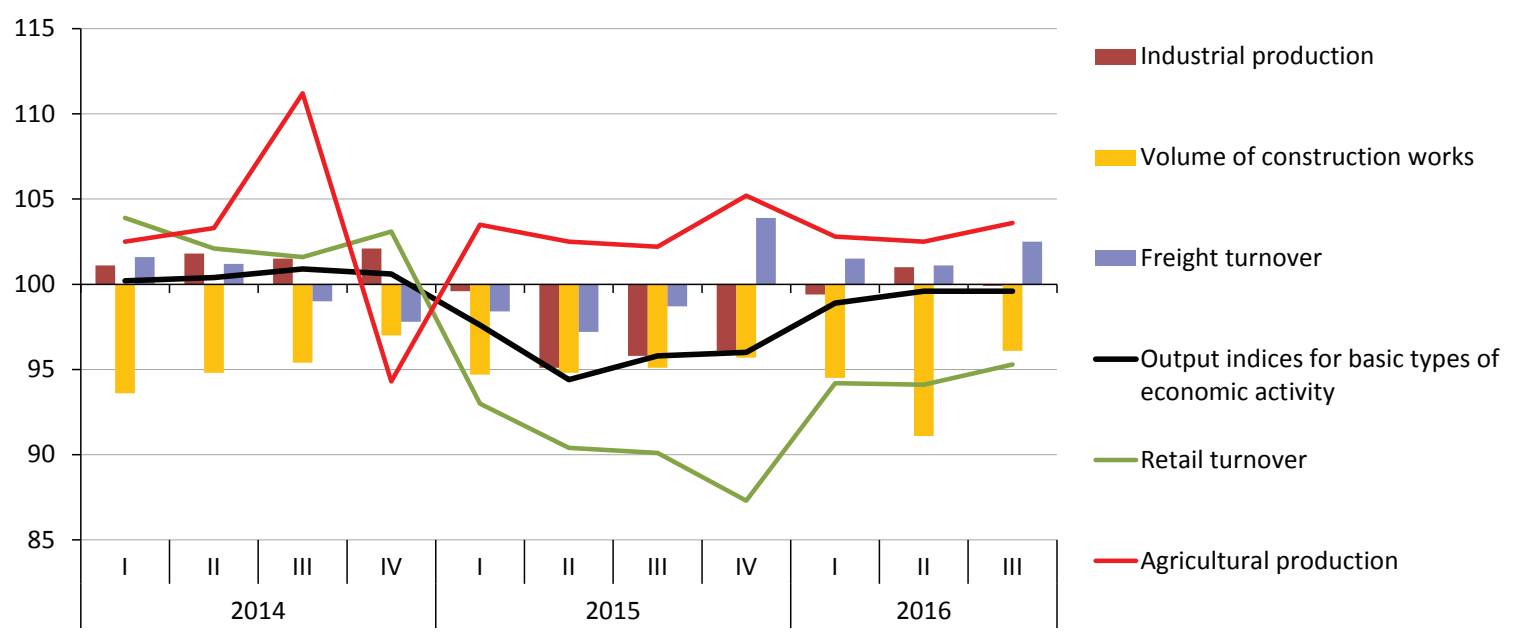

Source: Rosstat.

Fig. 1. The growth rates in 2014-2016 by basic type of economic activity, relative to the corresponding quarter of previous year, as \% 
shrinkage of household final consumption expenditure (HFCE) and gross fixed capital formation (GFCF), as well as tangible current asset growth. Besides, since early 2016, due to Russia's prevalent economic development model, the plunge of exports (76.6\% relative to January-September 2015 ) has been deeper than that of imports (96.0\%), and so the input of exports in the overall GDP index has begun to shrink noticeably.

The situation is further complicated by the simultaneous shrinkage of consumer and investment demand. The downward trend in consumer demand has been caused by the corresponding dwindling, for eight quarters in a row, of the personal income index. The household final consumption expenditure index in $\mathbf{2 0 1 6}$ has been on the decline, while similar trends have also been displayed by retail trade turnover and the market for commercial services rendered to the population. The lowest point of retail trade turnover decline was passed in Q4 2015, when real wage hit its record low of the entire 16-year observation period. The population responded to changes in the level and structure of consumer prices coupled with a high inflation rate by radically reducing the demand for non-food products, followed by a less steep plunge of the demand in the consumer food market. Later on, when in early 2016 people gradually became to be better adapted to the new market situation, and the pressure of postponed consumer demand became stronger, the quarterly indices began to demonstrate less prominent downward trends in consumer goods turnover across various segment of the consumer market. In Q2 and Q3 2016, as the real wage growth index slipped into positive zone relative to its movement pattern observed over the same period of the previous year, the pressure in the consumer market somewhat receded, while the failure of real allotted pensions, social benefits and wages to catch up with the pace of changes in the market situation remained the topmost factor shaping the consumer behavior pattern.

The personal income structure over the first three quarters of 2016 was characterized by shrinking shares of wage, property income and entrepreneurial income alongside an increasing share of social benefits. It is this income structure coupled with the increasing socioeconomic differentiation

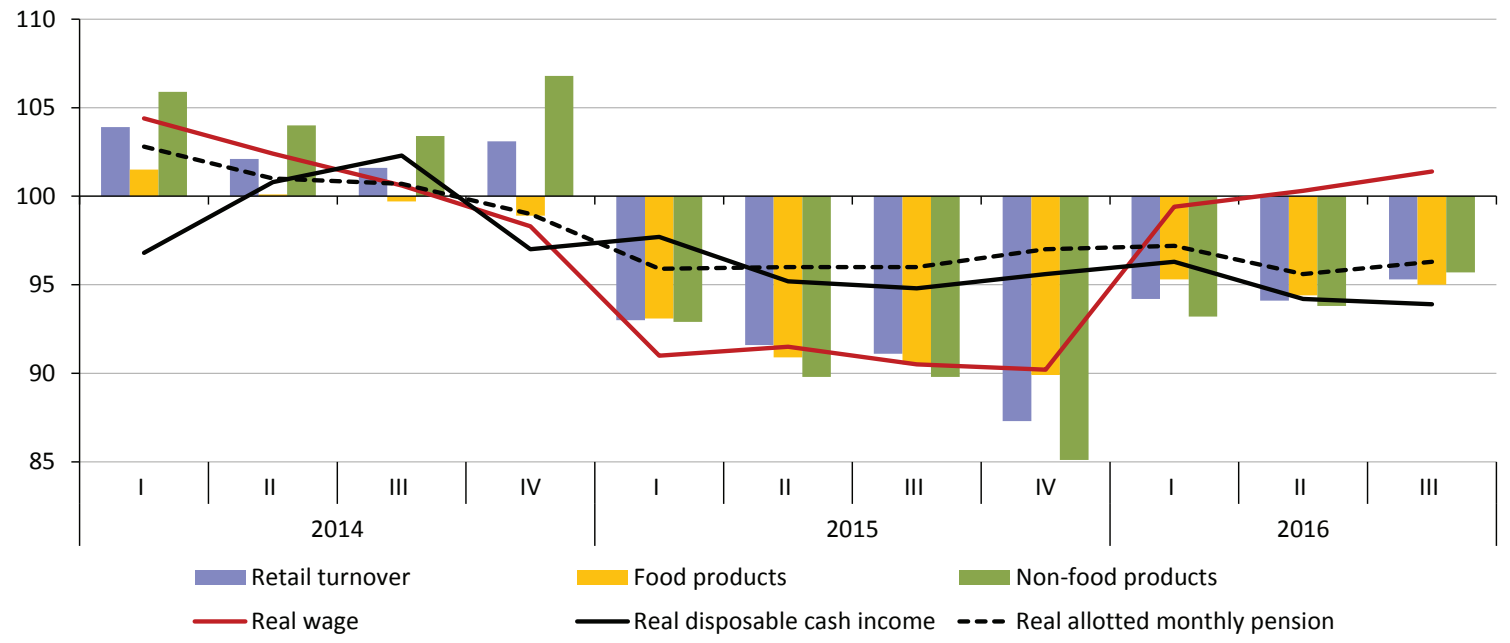

Source: Rosstat.

Fig. 2. The movement of the retail turnover and real personal income indices in 2014-2016, as \%, relative to the corresponding quarter of previous year 
and the currently observed household final consumption expenditure patterns that are pushing down the consumer demand index.

It should be noted with regret that the positive trends observed in August and September 2016 could no longer be visible in October, and the standard of living continued its plunge in per annum terms: the real personal income index amounted to $94.7 \%$, and that of real wage to $94.1 \%$. People reacted to the shrinkage of their personal income by reducing their demand for food

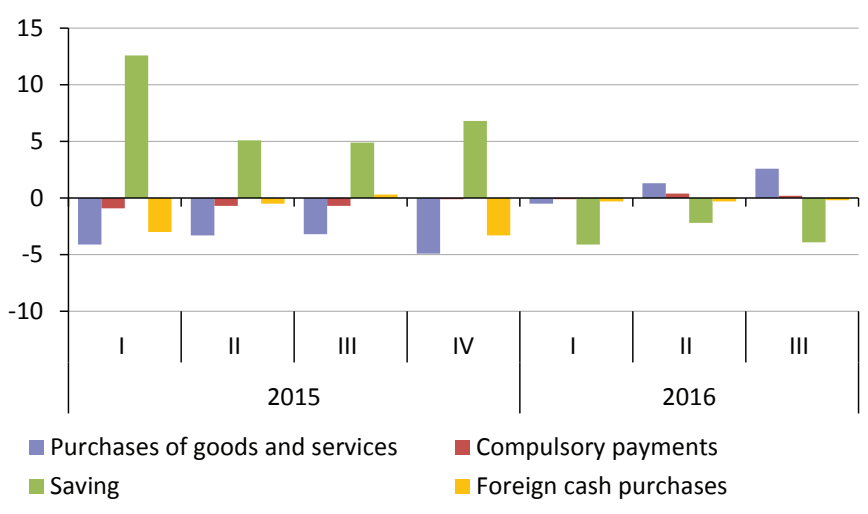

Source: Rosstat.

Fig. 3. The changes in the structure of consumption expenditure in 2015-2016 as \% of the same quarter of the previous year (pp) products by $6.2 \%$ and for non-food products by $3.4 \%$ relative to October 2015. In 2016, the two-year-old downward trend in the standard of living began to visibly affect the household consumption pattern: in face of plummeting personal income, people began to be less likely to save, and instead spent more on their daily consumption and compulsory payments. Over the period of January-September 2016, the share of saving in total personal cash income amounted to $10 \%$ vs. $13.4 \%$ a year earlier.

The main factors responsible for a slowdown in the investment processes have remained the restrictions imposed on borrowing in the foreign market and the high interest rates on loans offered by Russian banks. The volume of loans in nominal terms issued to non-financial organizations increased by $1.9 \%$ (as of September 1, 2016) compared with the same period of the previous year.

The main sources of investment in fixed assets are companies' own funds or government funding. In spite of the better financial result achieved by enterprises and organizations this year (growth by 1.21 times on JanuarySeptember 2015), both they and the banking sector are exercising caution in their decision-making concerning new investment programs, in view of the persistently unstable situation in the domestic market. However, it should be noted that recent quarter indices point to a gradual weakening of the trend toward curbing investment activity. The shrinkage of investment in fixed assets over January-September 2016 amounted to 2.3\% (vs. 9.6\% over January-September 2015), and that of the volume of construction work to $5.8 \%(5.1 \%)$, relative to the same period of the previous year. Although the construction work volume index is still on the decline, that of new housing units put on the market in Q3 2016 has moved into positive zone after its four-quarters-long plunge.

The currently low investment demand is observed alongside a declining construction materials production index (which amounts to $92.5 \%$ relative to January-October 2015) and a similarly shrinking demand for intermediate construction materials. A hope-inspiring factor is the rise, over the period of January-October 2016, in the industrial production index of machinery and equipment and in the imports of machinery and equipment - by 3.3\% and $2.3 \%$ respectively on January-September 2015. The noted changes in the main indices describing the situation in the construction sector and the 
movement of the investment-in-construction index point to an orientation towards recovery of the pre-crisis trends in the fixed capital renewal patterns, rather than to the creation of a new investment relations model.

Table 1

THE MAIN INVESTMENT ACTIVITY PARAMETERS IN 2014-2016, AS \% OF THE SAME QUARTER OF PREVIOUS YEAR

\begin{tabular}{|c|c|c|c|c|c|}
\hline Year & Quarter & $\begin{array}{c}\text { Investment } \\
\text { in fixed assets }\end{array}$ & GDP & $\begin{array}{c}\text { Construction } \\
\text { work volume }\end{array}$ & $\begin{array}{c}\text { Housing construction } \\
\text { projects, completed }\end{array}$ \\
\hline 2014 & Q1 & 94.7 & 100.6 & 93.6 & 130.9 \\
\hline & Q2 & 98.1 & 101.1 & 94.8 & 128.9 \\
\hline & Q3 & 98.5 & 100.9 & 95.4 & 116.4 \\
\hline & Q4 & 97.2 & 100.2 & 97 & 110.9 \\
\hline & Q1 & 95.2 & 97.2 & 94.7 & 133.5 \\
\hline & Q2 & 91.2 & 95.5 & 94.8 & 102 \\
\hline & Q3 & 87 & 96.3 & 95.1 & 93.8 \\
\hline & Q4 & 93.6 & 96.2 & 95.7 & 92.5 \\
\hline & Q1 & 95.2 & 98.8 & 94.5 & 83.7 \\
\hline & Q2 & 96.1 & 99.4 & 91.1 & 99.1 \\
\hline
\end{tabular}

Source: Rosstat.

The structural changes in Russia's economy observed in 2016 were determined by the increasingly prominent role of the raw materials sector and the related infrastructure segments. In October 2016, the production index in agriculture amounted to $2.4 \%$, and that in the mineral extraction sector to $0.8 \%$ (including extraction of fossil energy carriers - to $2.1 \%$ ) in per annum terms. It is noteworthy that in Q3 2016, as compared with Q3 2014, agricultural output gained $5.9 \%$, and output in the mineral extraction sector $-2.6 \%$.

The production output growth indices for October 2016 in the manufacturing industry and in the non-tradable products sector were in negative zone relative to the corresponding period of the previous year. Output in the manufacturing industry in Octobere 2016 amounted to 99.2\% in per annum terms relative to its previous year's value, and to 92.6\% relative to Q3 2014 .

The production output indices varied broadly between different branches of the manufacturing industry. Although the pace of decline has

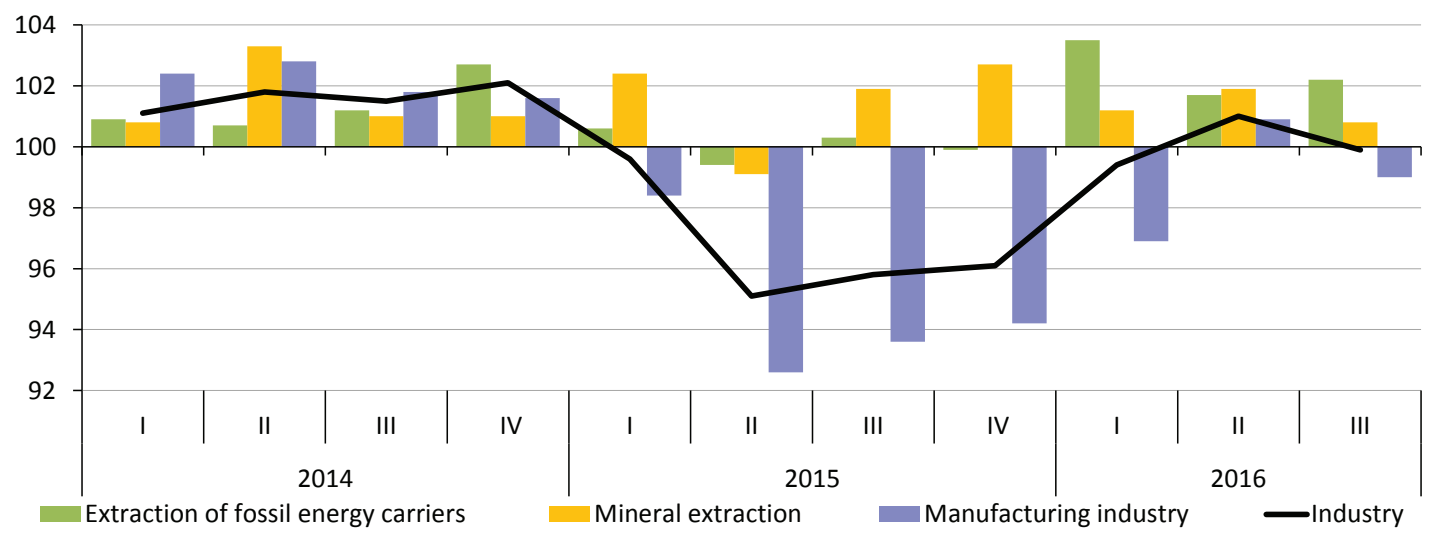

Source: Rosstat.

Fig. 4. The movement of industrial production indices, by type of economic activity, in 2014-2016, as a percentage of the corresponding quarter of the previous year 


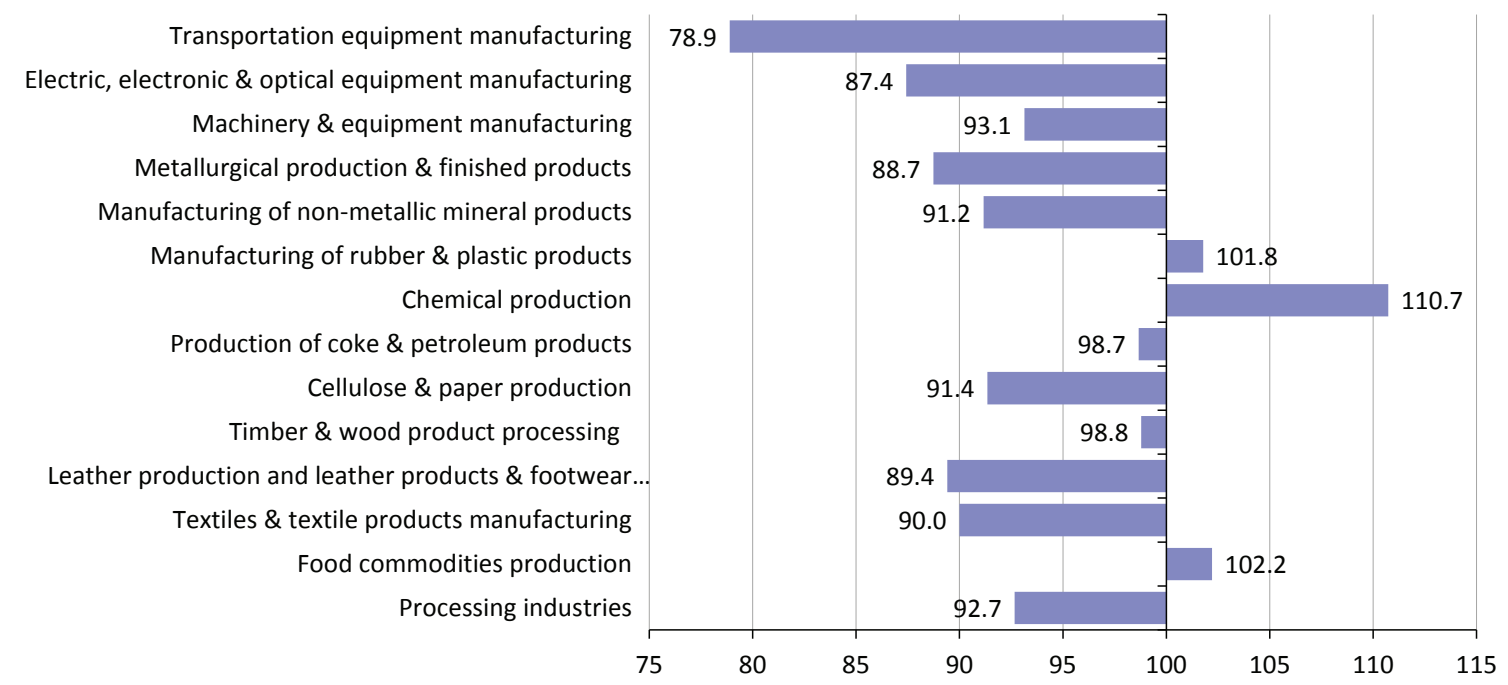

Source: Rosstat.

Fig. 5. The movement of manufacturing production indices, by type of economic activity, in Q3 2016, as \% of Q3 2014

been gradually weakening, and some positive movement was once again observed in per annum terms, it is very important to consider the base effect when estimating the current situation and its future development prospects. A comparative analysis of the behavior of output indices by type of economic activity in 2016 with that in Q3 2014, when the manufacturing industry could still boast of some growth potential, demonstrates that recovery growth has truly occurred only in the chemical industry, the production of rubber and plastic products, and the food industry. The sectors that are currently faced with the most serious production recovery issues are high-technology and medium high-technology machine-building. In October 2016, these continued to display negative growth rates in per annum terms.

Over the period of January-October 2016, the total number of employed persons increased by $0.9 \%$, and the number of officially registered unemployed individuals - by $0.6 \%$ on the corresponding period of 2015. The unemployment rate (as estimated by the ILO methodology: the ratio of the number of unemployed individuals to the total labor force number) in October 2016 amounted to $5.4 \%$.

The employer demand for workforce (estimated on the basis of applications filed with the local bodies of the Federal Service for Labor and Employment) has remained above its last year's level; the tension coefficient (the number of registered unemployed individuals per 100 job vacancies) in September 2016 was 73.2 vs. 83.9 a year earlier. In compliance with the established tradition in Russian practices, labor market adjustment in crisis situation is mainly achieved by means of wage cuts, part-time employment, workforce spillover into the 'informal employment' sector, and not through an automatic surge of the unemployment rate. This phenomenon reflects not only the level of labor force mobility, but also the weakness of government institutions responsible for labor market regulation.

The Russian economy is currently faced with some acute problems caused by an inefficient distribution of production factors. The low investment demand remains the main short- and medium-term risk factor. 